\title{
Study of Pulmonary Functions in Air Conditioned Car Drivers: A Cross-sectional Study
}

\author{
${ }^{1}$ S. P. Choudhari, ${ }^{2}$ R. S. Doiphode, ${ }^{3}$ U. S. Zingade, ${ }^{4}$ Khaled Mohsin Badaam \\ Ahmed Munibuddin \\ Department Of Physiology, Govt. Medical College, Aurangabad.
}

\begin{abstract}
:
Background: Extensive use of air-conditioners (ACs) indoor as well as while travelling in cars has increased the risk of atopic sensitization and it may alter lung function as it not only controls temperature but also has a profound effect on surrounding environment.

Objective: To evaluate the spirometry parameters of air conditioned car drivers.

Design: The present study was carried out on 25 male air conditioned car drivers in the age-group of 20-40 years who were employed as AC car tourist taxi drivers since last 3 years and having exposure to ACs in cars for greater than 2 hours/day. Spirometry parameters such as Forced Vital Capacity (FVC), Forced Expiratory Volume in the first second $\left(F E V_{1}\right)$, Forced Expiratory Flow [FEF $\left.F_{(25-75 \%)}\right]$, and Maximum Voluntary Ventilation $(M V V)$ were evaluated. The results were compared with that of the age, sex and socioeconomic status matched control subjects.
\end{abstract}

Results: $F V C, F E V_{1}, F E F_{(25-75 \%)}$ and $M V V$ showed a significant decline in air conditioned car drivers as compared to controls.

Conclusions: Air conditioned car drivers have significantly reduced lung function parameters compared to control subjects as measured by spirometry.

Keywords: Spirometry, Plethysmography, Air Conditioners, Car Drivers.

\section{Introduction}

Today's modern lifestyle and raised living standards have led to increased use of machines and electronic goods by common man. Air conditioners, popularly known as AC are one of them. AC makes use of refrigerant materials like ammonia, non halogenated hydrocarbons like methane and works on principle of refrigeration cycle. They decrease the absolute humidity of air and make it dry. There is a cold condenser coil which condenses water vapour and this formed water can be removed by drain .Hence, AC makes the air cool and dry. [1] It is this cool and dry air which can cause bronchoconstriction and increase airway resistance [2, 3]. Increased airway resistance is detrimental to the air movement through the respiratory passages and affects respiration .This is reflected as decreased pulmonary function tests (especially FEV1, PEFR, FEF25-75\%). Long term use of ACs is being implicated in the causation of obstructive disease like pattern [4]. The present study was conducted to evaluate the spirometry parameters in car drivers with exposure to AC over a long period.

\section{Materials And Methods}

Study Design: Cross-sectional Study.

Cases: 25 male air conditioned car drivers in the age-group of 20-40 years who were employed as AC car tourist taxi drivers since last 3 years and having exposure to ACs in cars for greater than 2 hours/day were studied at Pulmonary Function Test (PFT) laboratory, Department of Physiology, Govt. Medical College, Aurangabad.

Controls: Age, height, weight matched healthy subjects of same number from similar socioeconomic status were selected as controls for the study.

Subjects with past history of major respiratory illness like Tuberculosis, pleural effusion, COPD, asthma \& smokers were excluded from the study.

PFT were recorded on Whole Body Plethysmograph (Elite Dx model Med graphics, USA).

Spirometry parameters like FVC, $\mathrm{FEV}_{1}, \mathrm{FEF}_{(25-75 \%)}$ and MVV were recorded in sitting position outside the body box of machine. The standard protocol and precautions for the spirometry procedure as per American Thoracic Society guidelines were followed. Three recording were taken and the best effort was included in the results. All the recordings were done between 9 am to $11 \mathrm{am}$ to eliminate any effect of diurnal variation. Percent predicted values for all the parameters were taken into consideration for statistical analysis to eliminate the effect of confounding factors like Age, height, weight on different lung parameters.

Unpaired ' $t$ ' test was applied for comparison between the two groups. 
III. Results

Table1: Baseline Characteristics

\begin{tabular}{|l|l|l|}
\hline Parameter & Cases & Controls \\
\hline Age (years) & $28.2 \pm 6.1$ & $29.4 \pm 6.5$ \\
\hline Weight (kilograms) & $64.7 \pm 7.7$ & $62.5 \pm 9.2$ \\
\hline Height (centimeters) & $165.1 \pm 6.8$ & $164.6 \pm 7.1$ \\
\hline BMI $\left(\mathrm{kg} / \mathrm{m}^{2}\right)$ & $23.46 \pm 2.32$ & $23.07 \pm 2.15$ \\
\hline
\end{tabular}

Table 2: Comparison of percent predicted values of Lung Functions

\begin{tabular}{|l|l|l|l|}
\hline \multirow{2}{*}{ Lung Parameters } & Test Group & Control group & \multirow{2}{*}{ 'p' value } \\
\cline { 2 - 4 } & Mean \pm SD & Mean \pm SD & \\
\hline FVC $(\%$ predicted $)$ & $54 \pm 9.7$ & $78.9 \pm 6.4$ & $0.0001^{* *}$ \\
\hline FEV1 $(\%$ predicted $)$ & $56.1 \pm 5.8$ & $73.5 \pm 4.9$ & $0.0001^{* *}$ \\
\hline FEF $25-75 \%$ (\% predicted $)$ & $70.6 \pm 16.8$ & $89.9 \pm 14.3$ & $0.0001^{* *}$ \\
\hline MVV $(\%$ predicted $)$ & $78.4 \pm 17.3$ & $99.7 \pm 13.3$ & $0.0001^{* *}$ \\
\hline
\end{tabular}

** Highly significant

\section{Discussion}

Present study indicates that the AC car drivers had significantly lower lung volumes and capacities when compared with controls.

The decreased values of lung functions may indicate underlying lung dysfunction due to exposure to AC environment. Due to cold air inhalation, airway becomes hyper-responsive [5, 6]. Bronchoconstriction occurs and it increases resistance of airways. The mechanism causing bronchoconstriction is vagal mediated nervous reflex [7]. The other factor behind it is increase in the number of mast cells. They release histamine which is a known agent causing bronchoconstriction [8,9]. Cold air also causes epithelial desquamation and loss of epithelial derived relaxation factor which leads to bronchoconstriction [10]. Repeated cooling and desiccation also causes airway remodeling same as that of asthma $[11,12]$. It also removes the protective mucosal barrier which exposes underlying sub mucosa [10]. This leads to inflammatory changes and increase in the number of eosinophils [13].

Similar study was done in 2006. Farah $\mathrm{K}$ et al did the pulmonary function tests to assess the effect of air conditioners (AC) on pulmonary functions in 10 young healthy non-smoker males who were using AC's in their cars for at least $1 \mathrm{hr}$ daily since last 6 months and ten subjects who did not use AC acted as controls. The parameters PEFR, FEF25-75\% and FEV1 were significantly reduced in subjects using car AC's [14].

Hiteshkumar Solanki et al in 2013 performed spirometry to observe the effect of air condition (AC) on pulmonary functions. The study group contained 30 subjects who were using AC in their cars for at least 2 hours daily since last 6 months and 30 age and sex matched subjects who did not use AC acted as controls. The pulmonary functions were assessed using spirometry. PEFR and FEF25-75\% were significantly decreased in AC users. [15]

In 2013, Sandip Hulke did spirometry to study the effect of AC on pulmonary function. Pulmonary function test was done and parameters observed were FVC, FEV1, FEV1/FVC, PEFR, MVV and FEF 25\%. All the parameters except FEF were decreased in AC users. Hence, the results were suggestive of mild airflow obstruction in AC users [4].

Sabade SB in 2013 performed spirometry to study the effect of AC on pulmonary function tests. The parameters studied were, FEV1, FVC, PEFR and MVV. It was found that in AC users, the values were lower as compared to non users. [16]

Limitation of the present study is small sample size and cross-sectional study design which makes it difficult to evaluate time dependent derangements in lung function. Further research especially cohort studies and multicentric studies needs to be done in AC car drivers to substantiate the study results.

\section{Conclusions}

The study revealed that AC car drivers had significantly reduced spirometry parameters when compared with age, sex and socio-economic status matched controls.

\section{Recommendations:}

1) AC car drivers should undergo pulmonary function tests regularly to detect any changes at an earlier stage.

2) Use of humidifiers, heat and moisture retaining masks which can compensate for the dry air of AC can be studied.

Acknowledgements

The authors are thankful for the active participation of all the study participants. 


\section{References}

[1]. Malcolm J.J.History of air conditioning. Newsweek Winter 1997;130(24):42-44.

[2]. Caire N,Cartier A, Ghezzo H, Malo J.L. Influence of the duration of inhalation of cold dry air on the resulting bronchoconstriction in asthmatic subjects. European Respiratory Journal.1989; 2: 741-745.

[3]. Fontanari P,Burnet H,Caroline M, Hartmann Z, and Jammes Y. Changes in airway resistance induced by nasal inhalation of cold dry, dry, or moist air in normal individuals. Journal of applied Physiology. October 1996; 81 (4):1739-1743.

[4]. Hulke SM, Thakare A, Patil P, Shete S.A, Vaidya Y.P. Pulmonary functions in air conditioner users. Medical Journal of Dr. D.Y. Patil University . January-March 2013; 6(1):21-24.

[5]. Beasley R Roche WR, Roberts T. Holgate ST. Cellular events in the bronchi in mild asthma and bronchial provocation.American Review Of Respiratory Diseases 1989;139:806-7.

[6]. Benson MK. Bronchial hyperreactivity.British Journal of Diseases of chest.1987;27;254-263.

[7]. Koskela HO. Cold air provoked respiratory symptoms:The mechanisms and management.International Journal of Circumpolar Health.2007;66:91-100.

[8]. Cruz AA, Togias A,Upper airway reactions to cold air.Curr Allergy Asthma rep.2008;8(2):111-7

[9]. Clark RA, Gallin JI, and Kaplan AP.The selective eosinophil chemotactic activity of histamine.Journal of Experimental medicine. 1987; 142-1462.

[10]. Iravani J and Melville G.N. Mucociliary function in the respiratory tract as influenced by physiochemical factors. Journal of Pharmacology.1989;B.(2):471.

[11]. Merre CL, Isber J, Chediak A.D and . Wanner. A. Effects of Cold Dry Air Nasal Stimulation on Airway Mucosal Blood Flow in Humans.Informa Healthcare.2003; 111( 4): 327-329.

[12]. Davis MS, Schofield B, Freed AN.Repeated peripheral airway hyperpnea causes inflammation and remodeling in dogs. Med Sci Sports Exerc; 2003 Apr;35(4):608-16.

[13]. Kuwahara Y, Kondoh J,Tatara K,Aznma E,Nakajima T and Hashimoto M et al.Involvement of urban living environment in atopy and enhanced eosinophil activity :Potential risk factors of airway allergic symptoms. Allergy 2001;56:224-230.

[14]. Khaliq F, Sharma S and. Tandon O.P.Pulmonary functions in air conditioner users. Indian Journal of Physiology and Pharmacology. 2006; 50 (1) : 67-72.

[15]. Solanki HK, Gojiya A.J, Dixit R and Jadeja J M. Study of pulmonary functions in air conditioner users and non users. I. J. A. B. M. S. JULY 2013

[16]. Sabade SB, B.B.Vikhe and borade N.G.Pulmonary ventilation in air conditioner users in Pravara rural hospital.Pravara Med Rev 2013 5(2):4-6. 